\title{
Preparation and Characterization of Manganese Slag and Fly Ash-based Geopolymer
}

\author{
Ya-guang Wang, Feng-lan Han ${ }^{\mathrm{a}}$, Shi-zhen Zhao and Jing-qiu Mu \\ Beifang University of Nationalities, Yinchuan 750021, China
}

\begin{abstract}
In this study, a series of manganese slag and fly ash-based geopolymers were prepared though alkali activation by varing the amount of manganese slag. The 3-day, 7-day and 14-day compressive strengths of these samples were tested. The maximum strength of $42.78 \mathrm{MPa}$ was obtained at 14th days of testing when $455 \mathrm{~g}$ of fly ash, $195 \mathrm{~g}$ of manganese slag, $20 \%$ of the alkali content, the curing temperature of $100^{\circ} \mathrm{C}$, the curing time of $12 \mathrm{~h}$ were used. XRD and FTIR characterization results shown that the polymerization reaction occurs between the glassiness in the manganese slag and the fly ash while adding alkali activator, and the main structure formed was Ca-A-S-H, which contributed the major strength in manganese slag and fly ash-based geopolymer.
\end{abstract}

\section{Introduction}

Fly ash is a slag obtained from the flue gas of coal-fired power plant. Electrolytic manganese slag is a by-product of the industrial production of manganese dioxide. At present, China's annual output of electrolytic manganese metal accounted for $98 \%$ of the global [1]. As a byproduct of electrolytic manganese metal, the electrolytic manganese slag production ratio was 1:7-10 manganese ore with agrade of $12-14 \%$, resulting in an annual electrolytic manganese slag production rate of approximately 8-10 Mt [2]. The current allowable disposal method for electrolytic manganese slag is landfill, which can cause soil contamination, river or groundwater pollution and some other serious environmental pollution $[3,4]$. Duan et al determined that the main pollutants in the residue were manganese sulfate, ammonia nitrogen and heavy metals, such as cadmium and nickel. They also found that $13.7 \% \mathrm{Mn}, 17 \% \mathrm{Se}$, $44.09 \%$ ammonia and $55.3 \% \mathrm{SO}_{4}{ }^{2-}$ from raw materials entered residues [5]. Thus, for environmental protection and sustainable development purpose, how to re-utilize electrolytic manganese solid waste has been attracted extensive attention. One of the important way of recycling of manganese slag and fly ash is to use them to prepare the geopolymer material.

Geopolymer, as new green cementing material in recent years, is semi-crystalline aluminosilicate polymer based on Si-O and Al-O tetrahedron converted from amorphous structure. Geopolymer is not only showing excellent properties of organic polymer, ceramic and cement, but also can be prepared by some simple process with low cost [6]. Palomo and Hardjito et al indicated that the fly ash based geopolymer will be the key development way of cement for its wonderful mechanical properties and durability $[7,8]$. Kumar et.al used the slag

\footnotetext{
a Corresponding author: 625477897@qq.com
}

to substitute a part of preparation of fly ash geopolymer in their study, the results pointed that the C-S-H gel and $\mathrm{N}-\mathrm{A}-\mathrm{S}-\mathrm{H}$ gel were coexist in the reaction product and the addition of slag not only reduced the setting time but also high compressive strength of products [9]. D.Panias et.al investigated the effects of water, $\mathrm{NaOH}$ and sodium silicate on compressive strength of prepared fly ash based polymer [10]. Zhang Yunsheng et al studied the synthesis procedure of slag base material and the effect of heavy metal [11]. J.S.J.van Deventer et al analyzed the reaction mechanism of geopolymer materials prepared by solid waste [12].

In this study, we prepared manganese slag and fly ash-based geopolymer using manganese slag and fly ash as raw material, sodium silicate and sodium hydroxide as activator. On the effect of the added amount of manganese slag added on the compressive strength of geopolymer was studied. X- ray diffraction (XRD) and Fourier transform infrared spectroscopy (FIIR) were used to characterize the product of the geopolymer materials.

\section{Materials and experimental details}

\subsection{Raw materials}

Fly ash was obtained from a power plant in Ningxia. Manganese slag was obtained from Ningxia Tianyuan Manganese Industry Group. The alkaline activators used in this study were sodium silicate $\left(\mathrm{Na}_{2} \mathrm{SiO}_{3}\right)$ and sodium hydroxide (NaOH). NaOH (AR) was obtained from Tianjin Kermel Chemical Reagent Co. Ltd. $\mathrm{Na}_{2} \mathrm{SiO}_{3}$ $\left(\mathrm{SiO}_{2} / \mathrm{Na}_{2} \mathrm{O}=3.1\right)$ was obtained from Panyu chemical plant. The fly ash and manganese slag were placed the 
oven (DHG-9070A), baking 2 hours at $105^{\circ} \mathrm{C}$, grinding time was 2 hours in ball mill (SYMФ500).

Laser particle size instrument (Microtrac-X-100) to determine the size and distribution of fly ash and manganese slag, and the fly ash $\mathrm{d}_{50}$ was $18.47 \mu \mathrm{m}$ and the manganese slag $\mathrm{d}_{50}$ was $21.48 \mu \mathrm{m}$. Main constituents of fly ash and manganese slag were analyzed by chemical analysis. The chemical constituents of the fly ashes and manganese slag are given in Table 1.

Table1. Chemical component of raw materials(wt.\%).

\begin{tabular}{|c|c|c|}
\hline Materials & Fly ash & Manganese slag \\
\hline $\mathbf{C a O}$ & 5.37 & 9.24 \\
\hline $\mathbf{S i O}_{2}$ & 42.62 & 26.19 \\
\hline $\mathbf{A l}_{\mathbf{2}} \mathbf{O}_{3}$ & 19.85 & 4.66 \\
\hline $\mathbf{M g O}$ & 0.58 & 1.86 \\
\hline $\mathbf{F e}_{2} \mathbf{O}_{3}$ & 3.43 & 2.59 \\
\hline $\mathbf{T i O}_{2}$ & 0.54 & 0.12 \\
\hline Lost on ignition & 2.90 & 28.92 \\
\hline
\end{tabular}

Figure 1. shows the XRD of the fly ash. There is a diffuse hump at about $20-35^{\circ}$ meaning that the fly ash contains a certain amount of amorphous aluminosilicate minerals, and the main mineral phases are $\mathrm{SiO}_{2}$ and $\mathrm{Al}_{2} \mathrm{O}_{3} \cdot \mathrm{SiO}_{2}$. Figure 2. shows the XRD of the manganese slag. It show that the main mineral phases of the manganese slag are $\mathrm{CaSO}_{4} \cdot 2 \mathrm{H}_{2} \mathrm{O}$ and $\mathrm{SiO}_{2}$.

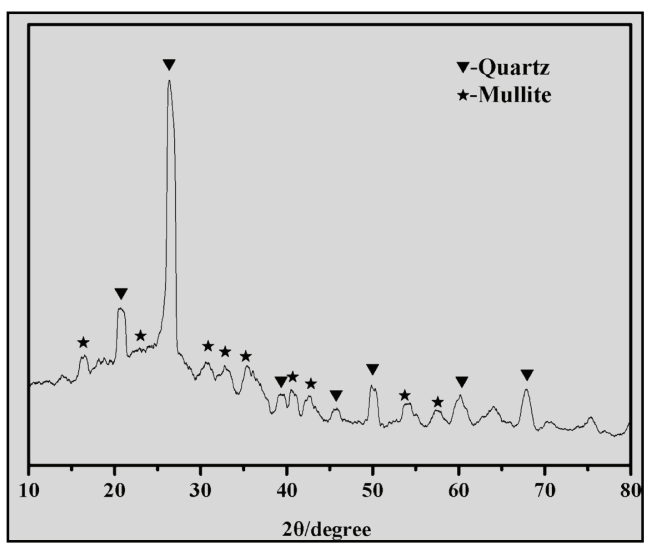

Figure 1. XRD of fly ash.

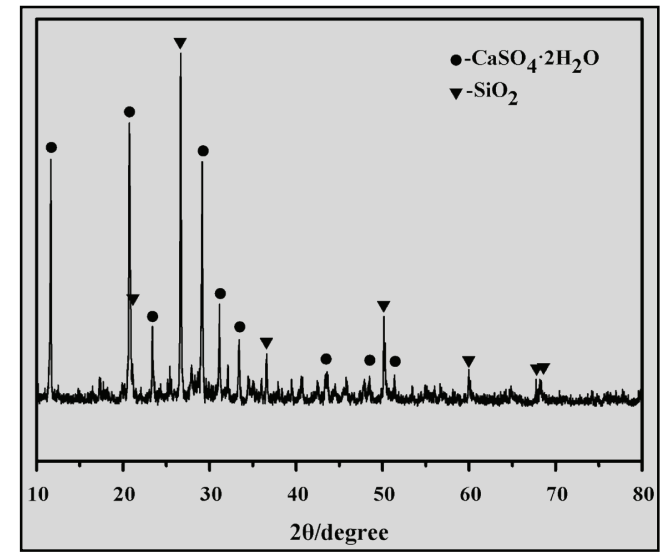

Figure 2. XRD of Manganese slag.

\subsection{Casting}

First, water, $\mathrm{NaOH}$ and $\mathrm{Na}_{2} \mathrm{SiO}_{3}$, were mixed throughly, and then cooled down to room temperature. The raw powder materials including fly ash and Manganese slag were weighed, and mixed together homogeneously for 12 min in a mixer at low speed. The mixed alkali solution was poured into a mixer and blended with the dry powder for 1-2 min at low speed, then for 3-4 min at high speed. Finally, the mixed paste was cast into $40 \times 40 \times 40 \mathrm{~mm}$ molds. The samples were cured at a temperature of $100^{\circ} \mathrm{C}$ for 12 hours. After that, the samples were kept at room temperature until the third day, seventh day and fourteenth day, when the tests were performed. A minimum of 3-6 samples was produced for each mix design to determine the average value of the compressive strength.

\subsection{Mole ratio of geopolymer}

The amount of alkaline activator used in this study was $20 \%$ of the total mass (except for the quantility of water). The used five different ratios of manganese slag / total solids were $0.1,0.2,0.3,0.4$ and 0.5 . The details of the mixtures are shown in Table 2.

Table 2. Mix design details.

\begin{tabular}{|c|c|c|c|}
\hline Fly ash(g) & $\begin{array}{c}\text { Manganes } \\
\text { e slag(g) }\end{array}$ & $\begin{array}{c}\text { Alkaline } \\
\text { activator }\end{array}$ & $\begin{array}{c}\mathbf{N a O H} \\
/ \mathbf{N a}_{2} \mathbf{S i O}_{3}\end{array}$ \\
\hline 585 & 65 & $20 \%$ & $2: 1$ \\
\hline 520 & 130 & $20 \%$ & $2: 1$ \\
\hline 455 & 195 & $20 \%$ & $2: 1$ \\
\hline 390 & 260 & $20 \%$ & $2: 1$ \\
\hline 325 & 325 & $20 \%$ & $2: 1$ \\
\hline
\end{tabular}

\subsection{Sample Characterization}

Pressure tester to test the compressive strength of the sample. Powder samples were used for X-ray diffraction (XRD) and Fourier transform infrared spectroscopy (FTIR) analysis.

The XRD analysis for the powder specimens was conducted using a shimazu XRD-6000 X-ray diffractometer, with a scanning rate of $4^{\circ} 2 \theta / \mathrm{min}$.

The FTIR spectra in the $1600-400 \mathrm{~cm}^{-1}$ range were recorded at $20^{\circ} \mathrm{C}$ using Spectrum 100 infrared analyzer.

\section{Results and discussions}

\subsection{Results of Compressive Strength}

The test results of compressive strength are shown in Figure 3. Figure 3. shows compressive strengths of 
manganese slag and fly ash-based geopolymers mortars up to $3,7,14$ days of curing. Results indicate that as the compressive strength increases, age of geopolymer sample increases, and as the content of manganese slag increases, strength of geopolymer increases and later decreases. When the amount of manganese slag was 30\%, the compressive strength was the highest. The decrease of the activator efficiency may be a result of some components of manganese slag reacted with activator while the addition of manganese slag increasing. Therefore, the compressive strength decreased.

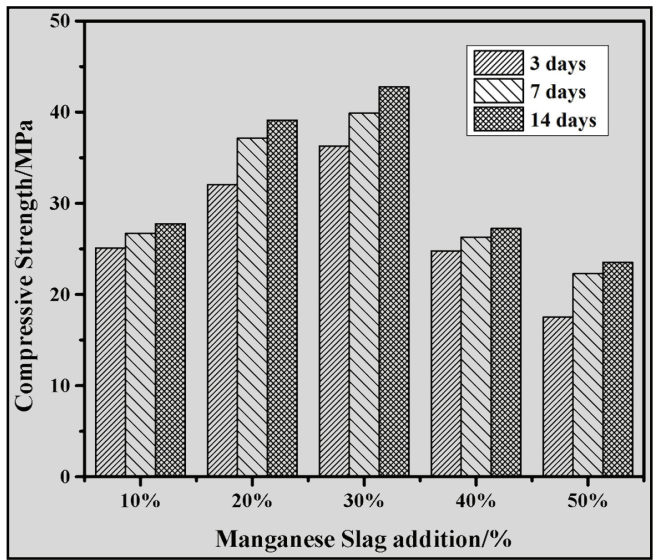

Figure 3. Variation of compressive strength of geopolymer specimens as function of manganese slag content.

\subsection{Results of XRD analysis}

X-ray diffractograms for different addition amounts of manganese slag and fly ash based geopolymer at 14 curing days are shown in Figure 4. It demonstrated that the crystal in the geopolymer were $\mathrm{SiO}_{2}$, $\mathrm{NaAl}\left(\mathrm{SO}_{4}\right)_{2} \cdot 6 \mathrm{H}_{2} \mathrm{O}, \quad \mathrm{CaAl}_{2} \mathrm{Si}_{2} \mathrm{O}_{8} \cdot 4 \mathrm{H}_{2} \mathrm{O}$ and $\mathrm{Na}_{2} \mathrm{SO}_{4}$. Compared with XRD of fly ash(Figure 1), the diffuse hump decreased and shifted to the right, illustrating that amorphous aluminosilicate minerals reacted with activator $\left(25-40^{\circ}\right)$. Part of quartz and mullite crystal phase convert to amorphous structure with the reaction processing, and $\mathrm{Ca}-\mathrm{A}-\mathrm{S}-\mathrm{H}$ gel was formed in the alkaline environment. Ca-A-S-H gel was the main source of the compressive strength of manganese slag and fly ashbased geopolymer.

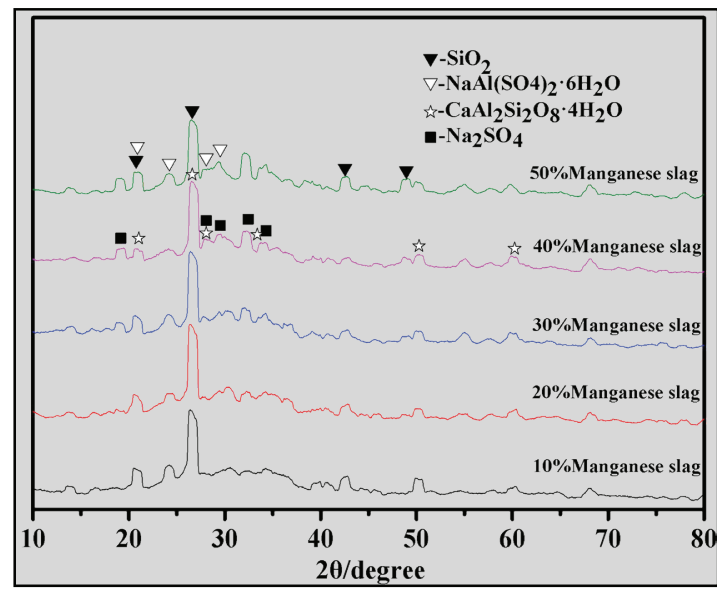

Figure 4. XRD of different addition amounts of manganese slag and fly ash based geopolymer for 14 days.

\subsection{Results of FTIR analysis}

Figure 5. is the FTIR spectra of different addition amounts of manganese slag and fly ash based geopolymer samples at 14 curing days . The asymmetric stretching vibration of $\mathrm{Si}-\mathrm{O}-\mathrm{Al}$ or $\mathrm{Si}-\mathrm{O}-\mathrm{Si}$ in the prepared geopolymer appears at $1122 \mathrm{~cm}^{-1}$. The peaks at $982 \mathrm{~cm}^{-1}$ and $668 \mathrm{~cm}^{-1}$ corresponded to $\mathrm{TO} 4(\mathrm{~T}=\mathrm{Si}$ or $\mathrm{Al})$ tetrahedral asymmetric and symmetric stretch vibration, respectively. The peak at $798 \mathrm{~cm}^{-1}$ was the $\mathrm{Si}-\mathrm{O}-\mathrm{Si}$ bending vibration bond. The absorption peak near $615 \mathrm{~cm}^{-}$ ${ }^{1}$ corresponds to the symmetric stretch vibration of Al-O$\mathrm{Si}$. The peak around $456 \mathrm{~cm}^{-1}$ was assigned to in-plane bending of Al-O and Si-O linkage. The appeared asymmetric stretch vibration absorption peak of Si-O$\mathrm{T}(\mathrm{Si}$ or $\mathrm{Al})$ indicated the formation of silicon oxygen tetrahedron and tetrahedral structure in the prepared geopolymer.

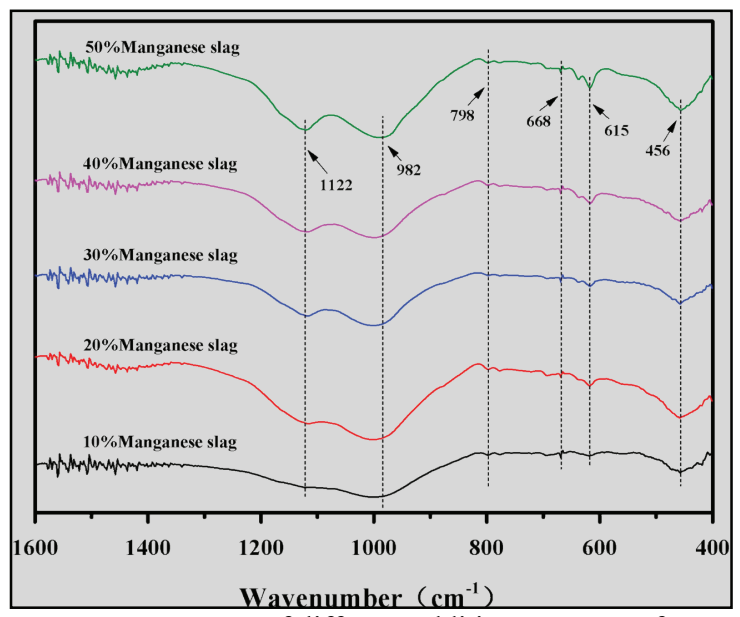

Figure 5. FTIR spectra of different addition amounts of manganese slag and fly ash based geopolymer for 14 days.

\section{Conclusion}

Based on this study, the following conclusions were drawn:

1. The optimum adding amount of manganese slag in fly ash is $30 \%$, and the strength is highest at this time, up to $42.78 \mathrm{Mpa}$. With the content of manganese slag further increasing, the activity of manganese slag decrease, which leads to decrease of the polymerization degree and the strength.

2. The XRD of the sample had Ca-A-S-H crystal, which indicates that the polymerization reaction is occurred. The new appeared asymmetric stretch vibration absorption peak of $\mathrm{Si}-\mathrm{O}-\mathrm{T}(\mathrm{Si}$ or $\mathrm{Al})$ in the FIIR spectra indicated the formation of silicon oxygen tetrahedron and tetrahedral structure in the prepared geopolymer. 


\section{Acknowledgments}

Thanks to China EU International Cooperation Project (SQ2013ZOG300003) and Ningxia Hui Autonomous Region science and technology support project (2014ZYH50).

\section{References}

1. Tan Z..In:The 5th international form of electrolytic Mn products market. (Changsha,Hunan,2013)

2. Bing Du, Changbo Zhou ,Zhigang Dan. Construction and Building Materials. 50,291(2014)

3. Duan N, Zhou CB, Yu XL. Resour Environ Yangtze Basin. 16,764(2007)

4. Su Y, Yuan XZ, Zeng GM, Li HM, Li L. Environ Prot Chem Ind. 29,300(2009)

5. Duan N, Wang F, Zhou CB, Zhu C, Yu H. Resour Conserv Recycl. 54,506(2010)

6. Xu. Hu. J. S. J. Van Deventer. International Journal of Mineral Processing. 3,247(2000)

7. Palomo A, Grutzeck M W, Blanco M T. Cement and Concrete R esearch. 29,1323(1999)

8. Hardjito D, Wallah S E, Sumajouw D M J. The Seventh CANMET ACI International Conference on Recent Advances in Concrete Technology. (Las Vegas, USA, 2004)

9. Kumar S, Kumar R,Mehrotra S P. Jounal of materials science. 45,607(2010)

10. Panias D, Giannopoulou I P, Perraki T. Colloids Surf, (Physicochem Eng Aspects), 1,(2007)

11. Zhang Yunsheng, Sun Wei, Chen Qianli. Journal of Hazardous Materials. 143 ,206(2007)

12. Van Deventer J S J, Provis J L, Duxson P. Journal of Hazardous Materials. 139,506(2007) 